\section{INTERSECTORAL MOBILISATION TO BRIDGE THE GAP BETWEEN RESEARCH AND PRACTICE IN WORK DISABILITY PREVENTION}

MF Coutu*, MJ Durand, The Mist-Caprit Team. Université de Sherbrooke, Longueuil, Quebec, Canada

\subsection{6/oemed-2018-ICOHabstracts.1584}

Introduction Best practices exist at the individual and organisational levels to facilitate return to work (RTW) following long-term absence for various health reasons. Yet implementation remains a challenge because of the complex multi-stakeholder context involving different social systems. The question then becomes, 'How can we bridge the gap between research and practice?'

Methods A collaborative research project based on a conceptual framework of sustainability science was used. The framework proposes phases and associated methods. Our study first sought to build a common vocabulary to help collaboratively frame a shared problem, using a group consensus technique. To ensure a common understanding of the problem among participants, we conducted a rapid literature review and held discussions with stakeholders on the effects of ethnocultural, gender and ageing factors on the RTW process in a work disability context where medical professionals have deemed workers ready to RTW following diverse health issues. We then used a consensus technique to enable participants to jointly construct possible solutions and establish research priorities regarding implementation of adapted best practices.

Results A total of 8 multidisciplinary researchers, 2 postdoctoral students, and 12 stakeholders representing patients, employers, unions, healthcare professionals, and legal and insurance systems participated. A bipartite (researcher/stakeholder) governance structure was put in place to facilitate the process. A tool to promote a common vocabulary was developed collaboratively and comprised 79 terms and definitions. To ensure common understanding of the problem, a summary was developed with the advisory and knowledge transfer committee in the governance structure, and a Web-based capsule was produced. A series of consensus groups identified 8 research priorities.

Discussion A collaboration between researchers and stakeholders that is structured by a conceptual framework allows them to jointly identify, in the short term, both the problem and possible activities to bridge the gap between research and practice.

\section{USING THE MEDICAL RESEARCH COUNCIL FRAMEWORK FOR THE DEVELOPMENT AND EVALUATION OF A RETURN-TO-WORK INTERVENTION FOR EMPLOYEES WITH BURNOUT}

\footnotetext{
${ }^{1,2} \mathrm{C}$ Lambreghts*, 1,2S Vandenbroeck, ${ }^{1,2} \mathrm{~L}$ Godderis. ${ }^{1}$ Centre for Environment and Health, University of Leuven, Leuven, Belgium; ${ }^{2}$ Groep IDEWE, External Service for Prevention and Protection at Work, Leuven, Belgium
}

\subsection{6/oemed-2018-ICOHabstracts. 1585}

Introduction Burnout is a work-related mental health problem and may cause long-term sickness absence. The aim of this study is to develop and assess the effectiveness of a return-to- work intervention that prevents long-term sick leave due to burnout. This intervention will be presented as a multidisciplinary care pathway for burned out employees on sick leave. The study started in January 2016 and will end in December 2019.

Methods We use the Medical Research Council framework to guide 4 phases: development, feasibility, evaluation and implementation. Based on a systematic literature review we made a first draft of the care pathway. During focus groups we discussed this first draft with professionals (i.e. general practitioners, psychologists, occupational physicians) to identify possible barriers and facilitators to implementing the care pathway (development). Next we will conduct a pilot study (feasibility) followed by a cluster randomised trial (CRT) (evaluation). Finally we will use the Reach, Effectiveness, Adoption, Implementation and Maintenance (Re-aim) framework to guide the implementation of the pathway.

Results We finished the systematic review and the focus groups. The systematic review showed that (partly) organisation-oriented return-to-work interventions have a positive effect on return to work. The focus groups revealed that professionals find it difficult to differentiate between burnout and other mental health problems (e.g. depression). They also have different opinions on burnout treatment and the role different stakeholders play during the return-to-work process isn't always clear for professionals. We continue working on the next phases.

Discussion Several stakeholders (employees, physicians, employers, psychologists) are involved in the care pathway. Therefore, improving communication between these stakeholders during the return-to-work process is an important focus in this study.

\section{FACTORS ASSOCIATED WITH SUPERVISOR SUPPORT OF JOB ACCOMMODATIONS FOR MENTAL HEALTH DISORDERS IN THE WORKPLACE}

\begin{abstract}
1,2,3,4 VL Kristman, ${ }^{5} \mathrm{M}$ Corbière, ${ }^{6}$ WS Shaw, ${ }^{7} \mathrm{~K}$ Harlos, ${ }^{8} \mathrm{M}$ Cernigoj. ${ }^{7}$ Department of Health Sciences, Lakehead University, Thunder Bay, Ontario, Canada; ${ }^{2}$ Division of Human Sciences, Northern Ontario School of Medicine, Thunder Bay, Ontario, Canada; ${ }^{3}$ Institute for Work and Health, Toronto, Ontario, Canada; ${ }^{4}$ Dalla Lana School of Public Health, University of Toronto, Toronto, Ontario, Canada; ${ }^{5}$ Université du Québec à Montréal, Montréal, Québec, Canada; ${ }^{6}$ Department of Family Medicine and Community Health, University of Massachusetts Medical School, Worcester, Massachusetts, USA; 'Department of Business and Administration, University of Winnipeg, Winnipeg, Manitoba, Canada; ${ }^{8}$ Centre for Employee Health, Safety and Wellness, Ontario Public Service, Toronto, Ontario, Canada
\end{abstract}

\subsection{6/oemed-2018-ICOHabstracts. 1586}

Introduction Supervisors of workers with mental health disorders (MHD) play a key role in the prevention of prolonged work absences. Providing appropriate workplace accommodation is one approach supervisors use to facilitate employees staying at work or returning to work early. People with MHD function well in the workplace when they are provided with appropriate work accommodations. Yet, we have little understanding of how factors influence the decision-making of supervisors to develop and provide work accommodations. Therefore, the objective of this study was to understand what factors determine whether workplace accommodations are supported and received from the perspective of supervisors and workers. 